|| ISSN(online): 2589-8698 || ISSN(print): 2589-868X || International Journal of Medical and Biomedical Studies

Available Online at www.ijmbs.info

Volume 3, Issue 2; February: 2019; Page No. 134-137

PubMed (National Library of Medicine ID: 101738825)

Index Copernicus Value 2017: 40.03

\title{
TO CORRELATE THE CHRONIC LOWER LIMB ISCHEMIA WITH COLORDOPPLER FINDINGS
}

\section{Dr. Ishant Kumar Chaurasia ${ }^{1} \&$ Dr. Muffazzal Rassiwala ${ }^{2}$}

${ }^{1} \mathrm{MS}$ (General Surgery), FIAGES, FMAS, Consultant Laparoscopic and Bariatric Surgeon, Anand Hospital, Indore

${ }^{2} \mathrm{MS}, \mathrm{MCh}$, Consultant Laprascopic Surgeon Shalby Hospital, Indore

Article Info: Received 4 February 2019; Accepted 26 February. 2019

Cite this article as: Chaurasia, Dr. I., \& Rassiwala, Dr. M. (2019). TO CORRELATE THE CHRONIC LOWER LIMB ISCHEMIA WITH COLORDOPPLER FINDINGS. International Journal of Medical and Biomedical Studies, 3(2).

DOI: https://doi.org/10.32553/ijmbs.v3i2.123

Address for Correspondence: Dr. Muffazzal Rassiwala, MS, MCh, Consultant Laprascopic Surgeon Shalby Hospital, Indore

Conflict of interest: No conflict of interest.

\section{Abstract}

Patient admitted in Anand Hospital, Indore from 2017 Dec to 2018 Dec to a minimum of 50 cases.

Total $1(2 \%)$ patient was found to have grade a abi, $13(26 \%)$ with grade $b$ abi, $5(10 \%)$ patients with grade $\mathrm{c}$ abi and 31 (62\%) patients with grade dabi. Color dopplerfindngs were consistent with clinical findings.

In color doppler diagnosed atherosclerosis patients, $13(50 \%)$ were those with raised serum cholesterol (grade a), 13 were grade b $(<250 \mathrm{mg} / \mathrm{dl}$ s. cholesterol) i.e. (50\%). While in buerger's disease 9 were found to be grade a (37.5\%) and 15 were found to be grade $b(62.5 \%)$. Higher association of grade a (>250mg/dl) was found with atherosclerosis.

Clinical study is very efficient, elaborative and explanatory in making the diagnosis of chronic lower limb ischemia and color doppler well conforms to the observations and deductions made by the clinical analysis in the study of PAD.

Keywords: Chronic, Lower Limb, Ischemia \& Colordoppler.

\section{Introduction:}

Chronic lower limb ischemia is a very common clinical occurrence in day to day out patients as well as admissions. The clinical spectrum of the disease is of a varied and elaborate nature. Therefore adequate management warrants a detailed understanding of all the aspects of the disease. $^{1}$

Chronic lower limb ischaemia is a clinical entity comprising of etiologies such as atherosclerosis, thromboangitis obliterans and other rare forms of non-specific and specific arteritis like SLE, Rheumatoid arteritis etc. which are rare. Though in western countries atherosclerosis predominates, in Indian subcontinent, thromboangitis obliterans is much more common. $^{2}$ The peculiarities of chronic lower limb ischaemia seen in our country is its incapacitating nature, morbidity being high, mortality very low, the etiopathology still unresolved and the treatment modalities unsatisfactory.

\section{Material \& Method}

Source of Data: Patient admitted in Anand Hospital, Indore from 2017 Dec to 2018 Dec to a minimum of 50 cases. 


\section{Method of Collection of data}

After admission data for my study is collected by

- $\quad$ Direct interview with patient and obtaining a detailed history.

- Through clinical examination,

- .Investigation performed over patient,

- A pre tested structural Performa will be used to collect this information for individual cases

Inclusion Criteria:

- Patients presenting with signs and symptoms of chronic lower limb ischemia like intermittent claudication, rest pain, ulceration, gangrene.

- Patients with evidence of lower limb ischemia on Doppler.

\section{Exclusion Criteria:}

- Patients with acute lower limb ischemia.

- Patients with pain and par aesthesia of traumatic, neurological or infective origin

- With no evidence of lower limb vascular occlusion on Doppler.

Results

Table 1: Ankle Brachial Index

\section{A. Color Doppler Finding}

\begin{tabular}{|l|l|l|l|}
\hline \multicolumn{5}{|l|}{ DIAGNOSIS } & Atherosclerosis & Buerger's Disease & Total \\
\hline ABI & 1 & 0 & 1 \\
\hline a & 3.85 & 0 & 2 \\
\hline b & 10 & 3 & 13 \\
& 38.46 & 12.5 & 26 \\
\hline c & 3 & 2 & 5 \\
& 11.54 & 8.33 & 10 \\
\hline d & 12 & 19 & 31 \\
& 46.15 & 79.17 & 62 \\
\hline Total & 26 & 24 & 50 \\
& 100 & 100 & 100 \\
\hline
\end{tabular}

Pearson Chi-Square $=6.480, \mathrm{DF}=3$ Likelihood Ratio Chi-Square $=7.079, \mathrm{DF}=3$

Atherosclerosis patients diagnosed with color doppler showed 1 patient with abi grade a (3.85\%) of the total atherosclerosis patients, 10 with grade $b(38.46 \%), 3$ with grade $c(11.45 \%)$ and 12 with grade $d$ (46.15\%). Buerger's disease patients showed none with abi as grade $a, 3$ as grade $b(12.5 \%), 2$ as grade c (8.33\%), 19 as grade $d(79.17 \%)$.

Total $1(2 \%)$ patient was found to have grade a abi, $13(26 \%)$ with grade $b$ abi, $5(10 \%)$ patients with grade $c$ abi and 31 (62\%) patients with grade dabi. Color dopplerfindngs were consistent with clinical findings 


\section{B. Color Doppler Finding}

\begin{tabular}{|c|c|c|c|}
\hline \multicolumn{4}{|c|}{ DIAGNOSIS } \\
\hline$A B I$ & Atherosclerosis & Buerger's Disease & Total \\
\hline $\mathrm{a}$ & $\begin{array}{l}13 \\
50\end{array}$ & $\begin{array}{l}9 \\
37.5\end{array}$ & $\begin{array}{l}22 \\
44\end{array}$ \\
\hline$b$ & $\begin{array}{l}13 \\
50 \\
\end{array}$ & $\begin{array}{l}15 \\
62.5\end{array}$ & $\begin{array}{l}28 \\
56 \\
\end{array}$ \\
\hline Total & $\begin{array}{l}26 \\
100\end{array}$ & $\begin{array}{l}24 \\
100\end{array}$ & $\begin{array}{l}50 \\
100\end{array}$ \\
\hline
\end{tabular}

Pearson Chi-Square $=0.791, \mathrm{DF}=1, \mathrm{P}$-Value $=$ 0.374 Likelihood Ratio Chi-Square $=0.794$, DF $=$ 1 , P-Value $=0.373$ Fisher's exact test: $\mathrm{P}$-Value $=$ 0.407429

In color doppler diagnosed atherosclerosis patients, 13 (50\%) were those with raised serum cholesterol (grade a), 13 were grade b (<250mg/dl s. cholesterol) i.e. (50\%). While in buerger's disease 9 were found to be grade a $(37.5 \%)$ and 15 were found to be grade $b$ (62.5\%). Higher association of grade a (>250mg/dl) was found with atherosclerosis.

\section{Discussion}

Ankle brachial pressure index was also studied in all the patients and grading was done according to the severity of stenosis i.e. grade $a=>0.9$ (normal), grade $b=0.8-0.89$ (mild ischemia), grade $c=0.5-0.79$ (moderate ischemia), grade $\mathrm{d}=<0.5$ (severe ischemia). More predilections of the latter two were seen in advanced disease with buerger's disease showing more inclination towards lower abpi. Similar results were observed in the study by Victor Aboyans et al in december $2012^{3}$.

Serum cholesterol values were taken for each patient. Two criteria were taken i.e. $a=>250 \mathrm{mg} / \mathrm{dl}$ and $b=<250 \mathrm{mg} / \mathrm{dl}$. Raised serum cholesterol values were observed in the patients with atherosclerosis while lower values were seen associated with buerger's disease patients. Diagnosis made by both clinical assessment and color doppler scan. Francisco J Hermano Fernando, Antonio Martin Conejero also took into account dylipidemia in their study in November 2007 and found such correlation ${ }^{4}$.

The age of all the patients were also compared among the two diagnoses of atherosclerosis and buerger's disease. In the current study mean age of patients with buerger's disease was found to be younger than that of atherosclerosis diagnosed both via clincal assessment as well as color doppler scan. These findings were consisent with the findings of Adar $\mathrm{R}$ et al in $1983^{5}$. Hartimath et al in 2017, ${ }^{2}$ and Perttu Et Arkkila in $2007^{6,7}$.

\section{Conclusion}

Clinical study is very efficient, elaborative and explanatory in making the diagnosis of chronic lower limb ischemia and color doppler well conforms to the observations and deductions made by the clinical analysis in the study of PAD.

\section{References}

1. Shead GV, Oomen RM, Savarirayan SS. The patterns of non-diabetic peripheral vascular disease in South India. Br J Surg. 1978;65:4953.

2. Hartimath BC, Mima Maychet B. Sangma. Clinical evaluation of chronic lower limb ischaemia and their management. 2017.

3. Aboyans V. Measurement and Interpretation of the Ankle-Brachial Index. 2012.

4. Hernando FJS, Conejero AM. Peripheral Artery Disease: Pathophysiology, Diagnosis and Treatment. 2007;60:969-82 - Vol. 60 Num.09.

5. Adar R, Papa MZ, Halpern Z, Mozes M, Shoshan S, Sofer B, Zinger $H$, Dayan $M$, 
Dr. Ishant Kumar Chaurasia et al, International Journal of Medical and Biomedical Studies (IJMBS)

Mozes E et al. Cellular sensitivity to collagen in thromboangiitis obliterans. N Engl J Med. 1983;308:1113-1116.

6. Perttu ET. Thromboangiitis obliterans (Buerger's disease). Published online 2006
Apr 27. doi: 10.1186/1750-1172-1-14. PMCID: PMC1523324.

7. Shionoya S. Management of chronic lower limb ischaemia. $\mathrm{Br} J$ Surg. 1988;75:259. 